EXTENDED REPORT

\title{
Increased circulating levels of tissue kallikrein in systemic sclerosis correlate with microvascular involvement
}

\author{
A Del Rosso, O Distler, A F Milia, C Emanueli, L Ibba-Manneschi, S Guiducci, M L Conforti, \\ S Generini, A Pignone, S Gay, P Madeddu, M Matucci-Cerinic
}

Ann Rheum Dis 2005;64:382-387. doi: 10.1136/ard.2004.023382

\begin{abstract}
See end of article for authors' affiliations

Correspondence to: Professor M Matucci Cerinic, Department of Medicine, Division of Rheumatology, University of Florence, Viale $G$ Pieraccini, 18-50139 Florence, Italy; cerinic@ unifi.it
\end{abstract}

Accepted 12 August 2004
Background: In systemic sclerosis (SSc) the lack of an angiogenic response to hypoxia may be due to inappropriate synthesis of angiogenic and angiostatic factors. Tissue kallikrein (t-kallikrein), regulating the kallikrein-kinin system and acting on the microcirculation, is a potent angiogenic agent, and kallistatin is its natural inhibitor.

Objective: To evaluate, in patients with SSc, t-kallikrein and kallistatin levels and their correlation with clinical features and measures of microvascular involvement.

Patients and methods: Serum levels of t-kallikrein and kallistatin (ELISA) and t-kallikrein skin expression (immunohistochemistry) were studied in patients with SSc, and evaluated for subset (dSSc or ISSc), clinical and immunological features, and microvascular involvement (ulcers, telangiectasias, nailfold videocapillaroscopy).

Results: Circulating levels of t-kallikrein were higher in SSc than in controls $(p<0.001)$. T-kallikrein did not differ between ISSc and dSSc, although it was higher in ISSc than in controls $(p<0.001)$.T-kallikrein levels were higher in patients with early and active capillaroscopic pattern than in those with late pattern $(p=0.019$ and 0.023$)$. Patients with giant capillaries and capillary microhaemorrhages had higher t-kallikrein concentrations than patients with architectural derangement $(p=0.04)$. No differences in kallistatin levels were detected between patients with SSc and controls, or between ISSc and dSSc. In early SSc skin, the presence of t-kallikrein was found in endothelial and in perivascular inflammatory cells, while no staining in skin of advanced SSc was detected.

Conclusion: T-kallikrein levels are increased in patients with SSc, particularly in ISSc, and are associated with early and active capillaroscopic patterns. T-kallikrein may play a part in SSc microvascular changes.
S ystemic sclerosis (SSc) is a connective tissue disease of unknown aetiology, resulting in fibrosis of the skin and internal organs. ${ }^{1}$ The pathogenesis of SSc includes microvascular alterations with perivascular inflammatory cell accumulation, abnormal collagen deposition, and immune dysfunction.

SSc microvascular involvement is characterised by endothelial injury, capillary abnormalities, and decay of angiogenesis, which lead to reduced blood flow, tissue ischaemia, and fingertip ulcers. ${ }^{2}$

In SSc, capillaroscopy provides evidence for capillary modifications, such as mega- and bushy capillaries from the early phases, ${ }^{3}$ which progress during the course of the disease, resulting in avascular areas with capillary dropouts in the advanced phase. ${ }^{4}$ Thus, angiogenesis in SSc varies significantly during the disease, and its progressive impairment may be a further mechanism aggravating tissue ischaemia and damage. ${ }^{2}$

In SSc, few reports focus on the modifications of angiogenesis..$^{5-7}$ Our group has shown that the proangiogenic vascular endothelial growth factor (VEGF), but not basic fibroblast growth factor, is significantly up regulated in patients with SSc from the first phases of the disease. ${ }^{8}$

Angiogenesis is tightly controlled by various inducers and inhibitors that are balanced under normal conditions, so that it does not occur in healthy tissues. In hypoxic environments, angiogenic inducers are activated and outweigh the inhibitors, thus initiating angiogenic processes. ${ }^{9}$

The kallikrein-kinin system (KKS), summarised in fig l, plays a part in vasorelaxation, in tissue perfusion, in regulation of growth factors, inflammation, and angiogenesis. ${ }^{10} 11$
All key components of the KKS are present in the vasculature and participate also in vascular remodelling. ${ }^{12}{ }^{13}$ Recently, attention has been drawn to the KKS as a recovery mechanism in ischaemic conditions. ${ }^{13}$

T-kallikrein (hKl or true tissue kallikrein) is a serine proteinase that cleaves low molecular weight kininogen to produce kinins. T-kallikrein is synthesised by endothelial and smooth muscle cells in the aorta as well as in medium and small vessels. ${ }^{14}$ Thus, t-kallikrein synthesised in vessels is involved, through kinins, in the regulation of vascular homoeostasis $^{14}{ }^{15}$ and in angiogenesis. ${ }^{15}{ }^{16}$ In fact, kinins may modulate a broad spectrum of vascular functions, including vasodilatation, plasma extravasation, and endothelial cell proliferation. ${ }^{10}{ }^{11}$

In patients with chronic peripheral vascular insufficiency, raised t-kallikrein levels were normalised after surgical revascularisation, ${ }^{17}$ suggesting that t-kallikrein increase might represent a compensatory response to chronic ischaemia, attempting to maintain an adequate tissue perfusion. ${ }^{17}$

Human kallistatin is a serine proteinase inhibitor that binds to t-kallikrein and inhibits its activity in vitro and in vivo. ${ }^{18}{ }^{19}$ Kallistatin is also a potent inhibitor of angiogenesis and tumour growth in vitro and in vivo by inhibiting VEGFand bFGF-induced proliferation, migration, and adhesion of cultured endothelial cells. ${ }^{20}$ Kallistatin has vasodilating

Abbreviations: ACA, anticentromere antibodies; dSSc, diffuse cutaneous systemic sclerosis; ELISA, enzyme linked immunosorbent assay; KKS, kallikrein-kinin system; ISSc, limited cutaneous systemic sclerosis; SSc, systemic sclerosis; VEGF, vascular endothelial growth factor 


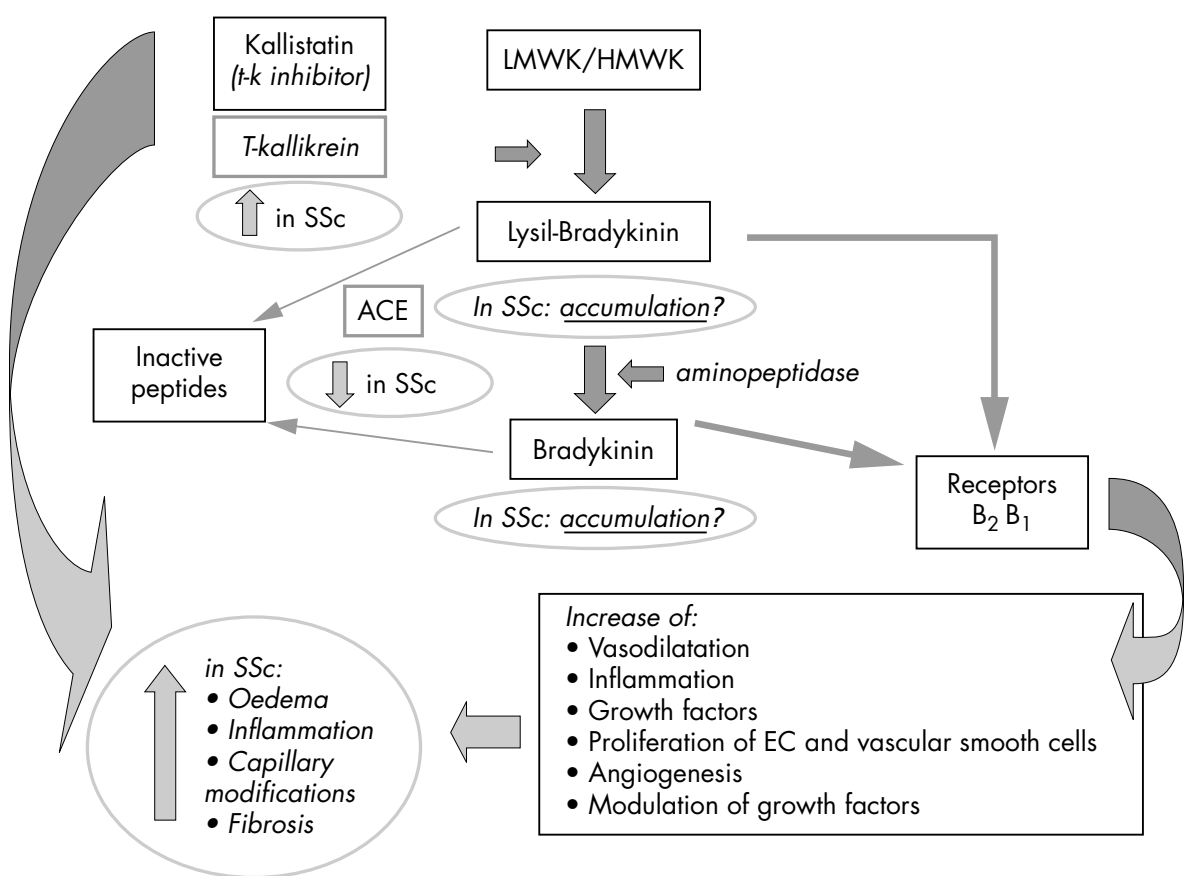

Figure 1 The kallikrein-kinin system (KKS) and its putative actions in SSc. T-kallikrein cleaves kinins (bradykinin and lysil-bradykinin) from low molecular weight kininogen (LMWK) and high molecular weight kininogen (HMWK). Kinins released from the vascular endothelium interact with $B_{1}$ receptors (constitutively expressed) and $B_{2}$ receptors (induced by tissue damage and inflammation) of endothelial and vascular smooth muscle cells. Kinins are rapidly inactivated mainly by angiotensin converting enzyme (ACE, kininase II). EC, endothelial cells.

effects independently from the KKS and inhibits angiogenesis in the rat model of hind limb ischaemia. ${ }^{21}$

This study aimed at analysing, in SSc, the circulating levels of the angiogenic factor t-kallikrein and of kallistatin, its natural inhibitor, to correlate them with the main clinical features and with measures of microvascular involvement, and at analysing the tissue localisation of t-kallikrein in the SSc skin by immunohistochemistry.

\section{PATIENTS AND METHODS}

Forty three consecutive white patients with SSc (37 women, 6 men) were recruited at the Department of Medicine, Section of Rheumatology of the University of Florence. Their median age was 61 years (range 24-79). Thirty five white healthy subjects matched for age and sex ( 28 women, 7 men with a median age of 59 years (range $31-75)$ ) served as controls.

The study was approved by the local ethical committee and written informed consent was obtained from patients and controls.

\section{Patient assessment}

Patients with SSc were classified as affected by limited cutaneous SSc (ISSc) or diffuse cutaneous SSc (dSSc). ${ }^{22}$ The disease duration was calculated from the onset of the first non-Raynaud's symptom.

All patients were receiving treatment with calcium channel blockers, proton pump inhibitors, clebopride, topical glyceryl trinitrate, and intravenous alprostadil- $\alpha$-ciclodestrine. Patients were not taking angiotensin converting enzyme inhibitors, corticosteroids, methotrexate, cyclophosphamide, D-penicillamine, iloprost, or other disease modifying drugs. Before sampling, they were washed out for 10 days from oral vasodilating drugs and for 2 months from intravenous alprostadil- $\alpha$-ciclodestrine.

Blood samples were drawn in the fasting state from patients and controls from the antecubital vein in the morning between 800 to $900 \mathrm{am}$.

\section{Skin and microvascular involvement}

At the time of blood drawing, the presence of fingertip ulcers, other skin ulcers (for example, at heels, legs, elbows, forearms), telangiectasias, and Raynaud's phenomenon was recorded. Skin involvement was assessed according to recent guidelines $^{23}$ and scored with the modified Rodnan skin score. $^{24}$

\section{Nailfold videocapillaroscopy}

After adaptation to room temperature $\left(20-22^{\circ} \mathrm{C}\right)$ for 15 minutes, nailfolds of all 10 fingers were analysed by nailfold videocapillaroscopy in each patient. The following features were examined: the presence of enlarged and giant capillaries, haemorrhages, loss of capillaries, disorganisation of the vascular distribution, and ramified/bushy capillaries. According to these features, patients were classified according to Cutolo et $a^{25}$ as follows: early pattern: few giant capillaries and capillary haemorrhages, relatively well preserved capillary distribution, no evident loss of capillaries; active pattern: frequent giant capillaries and capillary haemorrhages, moderate loss of capillaries with some avascular areas, mild disorganisation of the capillary architecture, absent or some ramified capillaries; late pattern: irregular enlargement of capillaries, few or absent giant capillaries, absence of haemorrhages, severe loss of capillaries with large avascular areas, severe disorganisation of the normal capillary distribution, frequent ramified/bushy capillaries. ${ }^{25}$

\section{Lung involvement}

Pulmonary function tests were performed in all patients. The carbon monoxide transfer factor (TLCO) by the single breath method, standardised for haemoglobin, was used as a measure of interstitial lung disease. ${ }^{26}$

\section{Autoantibodies}

Antinuclear antibodies (by indirect immunofluorescence on rat liver), anticentromere antibodies (ACA; by indirect immunofluorescence on HEp-2 cells and by enzyme linked immunosorbent assay (ELISA) for CENP antigen), and antitopoisomerase I antibodies (anti-Scl-70; by immunoblot analysis) were determined.

\section{Assay of t-kallikrein and kallistatin}

Blood was drawn, centrifuged ( $1500 \mathrm{~g}, 15$ minutes), and serum was collected and stored in aliquots at $-20^{\circ} \mathrm{C}$ until 
Table 1 Demographic and clinical characteristics of patients with SSc and controls*

\begin{tabular}{|c|c|c|c|c|}
\hline & $\begin{array}{l}\text { SSc } \\
(n=43)\end{array}$ & $\begin{array}{l}\text { Limited SSc } \\
(n=32)\end{array}$ & $\begin{array}{l}\text { Diffuse SSc } \\
(n=11)\end{array}$ & $\begin{array}{l}\text { ISSc } v \text { dSSc } \\
\text { ( } p \text { value) }\end{array}$ \\
\hline Age (years) & $61(24-79)$ & 63 (43-79) & 55 (24-79) & 0.13 (NS) \\
\hline Disease subset & & 32 & 11 & \\
\hline \multicolumn{5}{|l|}{ Sex } \\
\hline$M$ & 6 & 3 & 3 & \\
\hline $\mathrm{F}$ & 37 & 29 & 8 & \\
\hline \multicolumn{5}{|l|}{ Telangiectasias } \\
\hline+ & 26 & 18 & 7 & \\
\hline- & 17 & 14 & 4 & \\
\hline \multicolumn{5}{|l|}{ Fingertip ulcers } \\
\hline+ & 16 & 10 & 7 & \\
\hline- & 27 & 22 & 4 & \\
\hline \multicolumn{5}{|l|}{ Other skin ulcers } \\
\hline+ & 11 & 6 & 5 & \\
\hline- & 32 & 26 & 6 & \\
\hline Skin score & $10(3-41)$ & $8.5(3-30)$ & $21.50(16-41)$ & $<0.001$ \\
\hline \multicolumn{5}{|l|}{ Capillaroscopy } \\
\hline Early & 5 & 5 & 0 & \\
\hline Active & 31 & 25 & 6 & \\
\hline Late & 7 & 2 & 5 & \\
\hline \multicolumn{5}{|l|}{ Autoantibodies } \\
\hline ANA+ & 39 & 28 & 11 & \\
\hline Scl-70+ & 8 & 2 & 6 & \\
\hline $\mathrm{ACA}+$ & 16 & 16 & 0 & \\
\hline ANA - & 4 & 4 & 0 & \\
\hline TLCO (\%) & $69(26-144)$ & $75(35-144)$ & $54(26-102)$ & 0.003 \\
\hline
\end{tabular}

analysis. Immunoreactive t-kallikrein was measured, as previously described, ${ }^{17}$ in duplicate with an ELISA assay specific for the active form of the enzyme (AngioProgen, s.r.l., Sassari, Italy).

Immunoreactive kallistatin was measured, as previously described, in duplicate with a specific ELISA assay. ${ }^{27}$

\section{Immunohistochemistry for t-kallikrein}

Skin biopsy specimens were taken from the affected skin of the forearm of six patients with SSc (four women, two men; median age 60 years (range 28-75); median disease duration 5 years (range 1-20)), classified according to disease duration as early ( $\leqslant 3$ years) and advanced ( $\geqslant 3$ years)) and from six healthy controls matched for age and sex who underwent surgery for traumatic reasons.

The specimens were fixed in periodate-lysine-paraformaldehyde fixative. ${ }^{28}$ The tissue blocks were dehydrated in

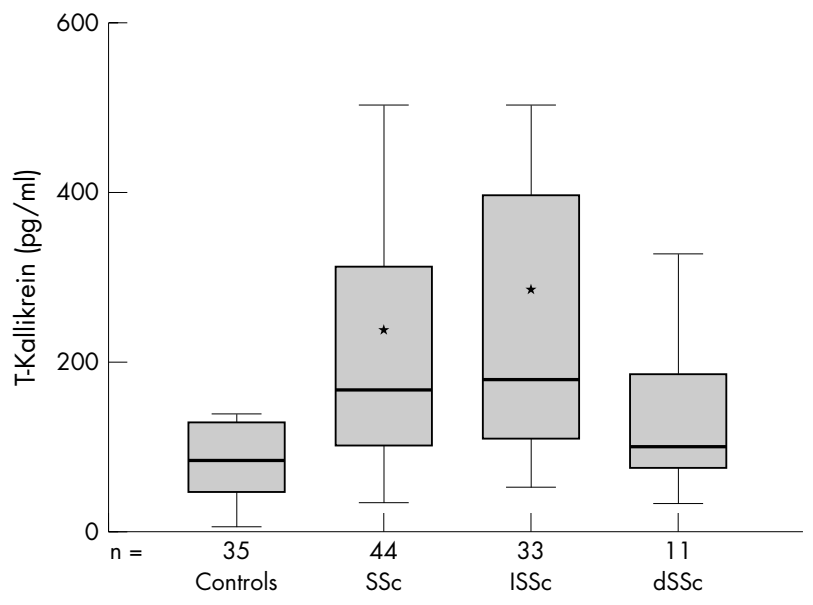

Figure 2 T-kallikrein levels in SSc, ISSc, dSSc, and controls. *Significantly higher versus controls. alcohol graded series and embedded in paraffin. Sections $(5 \mu \mathrm{m})$ were mounted on glass slides coated with polylysine.

The sections were incubated sequentially with primary rabbit polyclonal antibody raised against human t-kallikrein (1:1000; Calbiochem, UK), then with biotinylated goat antirabbit IgG. The immunoreactivity was detected using the avidin-biotin complex followed by binding horseradish peroxidase (Vectastain Elite ABC kit; Vector Laboratories, Burlingame, CA, USA). Control samples were prepared by omitting primary antibodies. All the sections were observed under a light microscope (Nikon Eclipse E400) and photographed by digital camera (Cool pix 2500 Nikon).

\section{Statistics}

Data are shown as box plots with median and upper and lower quartiles. Data were analysed using SPSS 11.5. Descriptive statistics were expressed as median and range
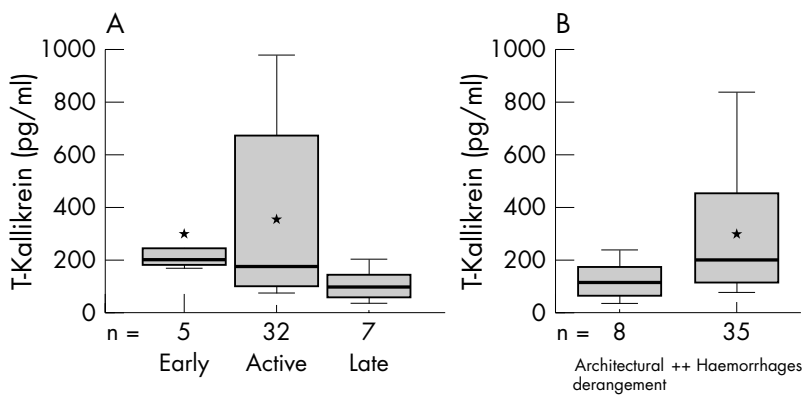

Nailfold capillaroscopy groups

Figure 3 (A) T-kallikrein levels in SSc according to capillaroscopic pattern (early versus active versus late); *significantly higher in early and active versus controls. (B) T-kallikrein levels according to single capillaroscopic changes (patients with giants capillaries and microhaemorrhages versus patients with architectural derangement of capillaries); "significantly higher in the group with haemorrhages and giant capillaries than in the group with architectural derangement. 

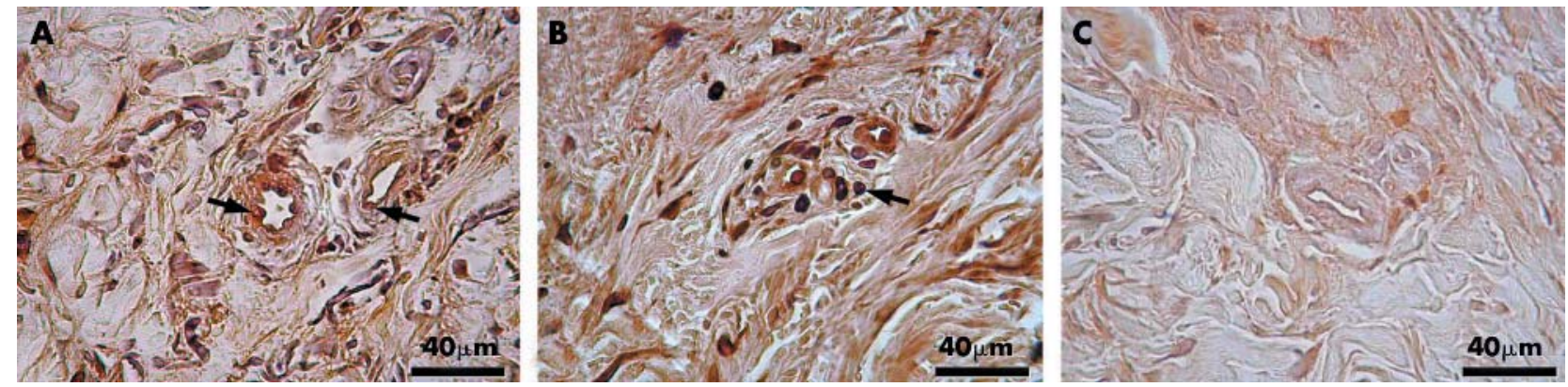

Figure 4 Skin sections. Immunostaining for t-kallikrein with diaminobenzidine revelation and Mayer's haematoxylin counterstaining. (A) Control: vessels with positive endothelial cells (arrows); (B) early SSc: small vessels show t-kallikrein staining in endothelial cells and in perivascular inflammatory infiltrate (arrow); (C) advanced SSc: no immunostaining for t-kallikrein is detected in the vessel wall.

for continuous variables, and as number and percentage for categorical variables. For continuous variables, the MannWhitney $\mathrm{U}$ test or the two tailed $t$ test was used for analysis between two groups, and the Kruskal-Wallis test (with post hoc Dunn test) for analysis of differences of more than two groups. Fisher's exact test was used for comparison of categorical variables. Non-parametric and parametric correlation analyses were performed with Spearman's rank correlation test and Pearson's test, respectively. Values of $\mathrm{p}<0.05$ were considered significant.

\section{RESULTS}

\section{Patients}

Table 1 shows the demographic and clinical characteristics of the patients with SSc. Thirty two patients had ISSc and 11 dSSc. ${ }^{22}$ The median disease duration was 5 years (range 2-36). According to capillaroscopic characteristics, 5 patients presented an early pattern, 31 patients had an active pattern, and 7 showed a late pattern. ${ }^{25}$ Patients with dSSc had higher values of skin score and lower TLCO $\%$ than patients with ISSc. Age and disease duration did not differ between the two subsets. None of patients with SSc have ever presented signs of "scleroderma renal crisis".

\section{Circulating levels of t-kallikrein and kallistatin}

Serum levels of t-kallikrein were significantly higher in patients with SSc (median $169 \mathrm{pg} / \mathrm{ml}$, range 35-2253) than in healthy controls (median $85 \mathrm{pg} / \mathrm{ml}$, range 7-689; $\mathrm{p}<0.001$; fig 2).

No difference was detected between ISSc (median $190.5 \mathrm{pg} / \mathrm{ml}$, range 54-2253) and dSSc (median $102 \mathrm{pg} / \mathrm{ml}$, range 35-328) and between dSSc and healthy controls, while t-kallikrein levels were higher in ISSc than in controls $(\mathrm{p}<0.001)$ (fig 2).

No differences in kallistatin levels were detected between patients with SSc (median $15.2 \mu \mathrm{g} / \mathrm{ml}$, range 0.960-240) and controls (median $15.0 \mu \mathrm{g} / \mathrm{ml}$, range 4.91-63.3), or between ISSc (median $12.0 \mu \mathrm{g} / \mathrm{ml}$, range 0.960-240) and dSSc (median $28.5 \mu \mathrm{g} / \mathrm{ml}$, range $7.81-226.0$ ) or between ISSc and dSSc versus controls.

The levels of t-kallikrein and kallistatin were positively correlated in healthy controls $\left(p=0.02, r^{2}=0.468\right)$, but not in SSc, or in ISSc or dSSc.

\section{Levels of $t$-kallikrein and kallistatin and autoantibodies, capillaroscopic and clinical features} In SSc, t-kallikrein levels did not differ significantly between patients with early (median $203 \mathrm{pg} / \mathrm{ml}$, range 174-399) and active capillaroscopy pattern (median 182 pg/ml, range 74 2253), but were both significantly higher than in patients with late capillaroscopy pattern (median $102 \mathrm{pg} / \mathrm{ml}$, range 35-204; $\mathrm{p}=0.01$ and 0.02, respectively; fig 3A).
As the features of each capillaroscopic pattern are different, but somewhat overlapping between early, active, and late groups, levels of t-kallikrein were also correlated with the single capillaroscopic changes. ${ }^{25}$ Levels of t-kallikrein were significantly higher in patients with giant capillaries and microhaemorrhages, characteristic of early and active capillaroscopic patterns (median $191 \mathrm{pg} / \mathrm{ml}$, range 76-2253) than in patients with architectural derangement (loss of capillaries and presence of ramified/bushy capillaries), characteristic of late capillaroscopic patterns (median 120 pg/ml, range 35236; $\mathrm{p}=0.04$; fig 3B).

No differences in age and in disease duration were found between patients with SSc with early, active, and late capillaroscopic patterns.

No significant correlation of t-kallikrein levels with age, disease duration, skin score, TLCO, telangiectasias, fingertip ulcers, and other skin ulcers was found. No significant differences in t-kallikrein levels were detected between patients with and without ACA antibodies, nor in Scl-70 positive patients compared with Scl-70 negative patients.

In SSc, kallistatin levels did not differ significantly between patients with early, active, and late capillaroscopy pattern. No significant differences in kallistatin levels were detected between patients with and without ACA antibodies, nor in Scl-70 positive patients compared with Scl-70 negative patients. No significant correlation of kallistatin levels with age, disease duration, skin score, TLCO, telangiectasias, fingertip ulcers, and other skin ulcers was found.

\section{Immunohistochemistry}

In the skin of healthy controls, vessels showed t-kallikrein expression in endothelial cells, smooth muscle cells, and in pericytes (fig 4A). A positive immunoreaction was also detected in the wall of the vessels near to and between hair follicles and skin glands.

In the skin of patients with early SSc (2/6 patients), positive immunoreactivity for t-kallikrein was seen in the endothelial cells of microvessels and in the perivascular inflammatory infiltrate in the papillary derma, near to the dermo-epidermal junction (fig 4B).

In the skin of patients with advanced SSc (4/6 patients), the few remaining vessels showed no immunostaining for t-kallikrein (fig 4C). Immunoreactivity was only detected in the endothelial cells of the few microvessels present between the scarce sebaceous glands and the few nerves that were still present.

\section{DISCUSSION}

Our data show that circulating levels of t-kallikrein, but not of kallistatin, are significantly modified in SSc. The source of the increased levels of t-kallikrein in patients with SSc remains unknown. T-kallikrein mRNA has been found in a 
variety of tissues and organs, such as kidney, adrenal and pituitary glands, pancreas, and endometrium. ${ }^{15}$ Probably, the sources of circulating t-kallikrein are endothelial cells, vessel smooth muscle cells, ${ }^{14}{ }^{16}$ or neutrophils, ${ }^{29}{ }^{30}$ whereas circulating kallistatin probably derives from endothelial and smooth muscle cells. ${ }^{14}$

In the blood stream, t-kallikrein contributes to reduction of vascular tone and increase of tissue perfusion in the microcirculation, to angiogenesis, and to the regulation of growth factors and inflammation, ${ }^{31}$ all mechanisms which are involved in SSc pathogenesis. ${ }^{1}$ Our data strongly suggest that the increase of t-kallikrein, not counteracted by a concomitant increase of kallistatin levels, correlates with an early and active derangement of the microcirculation. The t-kallikrein increase associated with early and active capillaroscopic pattern and/or with giant capillaries and microhaemorrhages, might be interpreted as a reaction to chronic ischaemia and/or as a frustrated attempt to provide effective angiogenesis through KKS enhancement.

In skin samples from patients with early SSc, t-kallikrein was detected in endothelial cells and in perivascular inflammatory infiltrate, whereas no staining was noticed in the skin from patients with advanced SSc, despite the rise in t-kallikrein circulating levels. A similar finding has already been seen in breast cancer, where prostate-specific antigen (hK3), a member of the kallikrein family, was raised in the serum of patients with breast cancer, but down regulated in tissue samples. ${ }^{33}$

These results suggest that in the early phases of SSC t-kallikrein may participate in the skin inflammatory process and in angiogenesis and that, later, synthesis at the vascular level is decreased, possibly owing to the functional exhaustion of endothelial cells.

In SSc, the reduction of vessel patency may consistently slow blood flow. T-kallikrein is activated by low flow and chronic ischaemia, and kinins generated by t-kallikrein may represent a compensatory mechanism helping to preserve tissue perfusion $^{34}$ (fig l). Our data are in agreement with those obtained in patients with chronic ischaemia, such as chronic peripheral vascular insufficiency, where high t-kallikrein levels were interpreted as a compensatory response to chronic arterial insufficiency, in order to maintain an adequate tissue perfusion. ${ }^{17}$

T-kallikrein, activating type IV collagenase, ${ }^{33}$ is deeply involved in angiogenesis. ${ }^{10} 13$ It favours the degradation of vascular basal membrane and extracellular matrix, essential for the first steps of angiogenesis. Kinins generated by t-kallikrein and acting by $B_{2}$ and $B_{1}$ receptors cause extravasation of plasma proteins, proliferation of endothelial cells, ${ }^{35-37}$ and stimulate the release of $\mathrm{NO}$ and prostaglandins ${ }^{38}$ that promote angiogenesis directly or by stimulating substance $\mathrm{P}$ and VEGF. ${ }^{38-40}$

In patients with SSc, serum levels of endostatin, a potent angiogenesis inhibitor, were found to be raised in the serum of patients with SSc and it was suggested that they played a part in the development of ischaemia. ${ }^{41}$ In contrast, we found normal levels of the angiogenesis inhibitor kallistatin. Thus, it is likely that the disturbance of KKS-induced angiogenesis is not related to a blockade of the biological effects of t-kallikrein by its specific inhibitor kallistatin. ${ }^{27}$ Therefore, high t-kallikrein levels, not counteracted by its inhibitor, may contribute, in damaged vessels, to the genesis of microhaemorrhages and giant capillaries.

Concurrence of different angiogenic growth factors is essential for reparative angiogenesis. The KKS shares important features with VEGF, such as plasma extravasation, vasodilatation, and endothelial cell proliferation. Our data show an increase of circulating t-kallikrein in patients with SSc, and up regulation of VEGF levels has also been reported in SSc by our group. ${ }^{8}$ Both t-kallikrein and VEGF may be triggered by hypoxia, ${ }^{77}$ but in SSc, despite their presence in high levels they cannot induce adequate angiogenesis.

The KKS may have a role in the development and maintenance of SSc also through kinins, whose tissue and circulating concentrations might also increase for the reduction of circulating angiotensin converting enzyme ${ }^{42}$ (fig 1). Kinins produced by t-kallikrein, by vasodilatation, and by plasma extravasation, lead to tissue oedema ${ }^{35}{ }^{36}$ and inflammation and may also become a potential trigger for fibroblast and vascular smooth muscle cell activation. ${ }^{43}{ }^{44}$

In the skin of patients with early SSc the presence of t-kallikrein in endothelial cells and in perivascular inflammatory infiltrate confirms the hypothesis that t-kallikrein is involved in the inflammatory process. T-kallikrein or other components of the KKS may amplify the production of inflammatory and fibrotic mediators, ${ }^{44-48}$ thus regulating a wide array of substances involved in SSc pathogenesis. Thus, the KKS system, particularly kinins, may contribute, in the early oedematous phase of SSc, to the development of "puffy digits" and, in more advanced phases, to the development of fibrosis. ${ }^{43}$

In the skin of patients with advanced SSc, the lack of t-kallikrein staining in most of the vessels suggests that the decrease of t-kallikrein synthesis at the vascular level is concomitant with the progressive involvement of the skin.

In conclusion, this study provides evidence for a rise in circulating t-kallikrein levels in SSc with early and active microvascular involvement and for participation of t-kallikrein in the early phases of the SSc skin inflammatory process. Further studies will investigate the functionality of receptors and downstream transcription factors of t-kallikrein and other components of the KKS in SSc.

\section{Authors' affiliations}

A Del Rosso, A F Milia, S Guiducci, M L Conforti, S Generini, A Pignone, M Matucci-Cerinic, Department of Medicine, Division of Rheumatology, University of Florence, Florence, Italy

O Distler, S Gay, Centre of Experimental Rheumatology, Department of Rheumatology, University Hospital of Zurich, Zurich, Switzerland C Emanueli, Molecular and Cellular Medicine, INBB, Alghero, Italy P Madeddu, Experimental Medicine and Gene Therapy, INBB, Osilo and Alghero, Italy; and Internal Medicine, University of Sassari, Sassari, Italy

L Ibba-Manneschi, Department of Anatomy, Histology and Forensic Medicine, University of Florence, Florence, Italy

\section{REFERENCES}

1 Clements PJ, Furst DE. Systemic sclerosis, 3rd ed. Baltimore: Williams \& Wilkins, 2003;(MD).

2 Matucci Cerinic M, Generini S, Pignone A. New approaches to Raynaud's phenomenon. Curr Opin Rheumatol 1997;9:544-54.

3 Maricq HR, Harper FE, Khan MM, Tan EM, LeRoy EC. Microvascular abnormalities as possible predictors of disease subsets in Raynaud phenomenon and early connective tissue diseases. Clin Exp Rheumatol 1983; 1:195-205.

4 Cutolo M, Grassi W, Matucci Cerinic M. Raynaud's phenomenon and the role of capillaroscopy. Arthritis Rheum 2003;48:3023-30.

5 Majewski S, Skopinska-Rozewska E, Jablonska S, Polakowski IJ, Pawinska M, Marczak $M$, et al. Modulatory effect of sera from scleroderma patients on lymphocyte-induced angiogenesis. Arthritis Rheum 1985;28:1133-9.

6 Koch AE, Litvak MA, Burrows JC, Polverini PJ. Decreased monocyte-mediated angiogenesis in scleroderma. Clin Immunol Immunopathol 1992;64:153-60.

7 Distler JH, Scheid A, Acker T, Hirth A, Rethage J, et al. Uncontrolled expression of vascular endothelial growth factor and its receptors leads to insufficient skin angiogenesis in patients with systemic sclerosis. Circ Res 2004;95:109-16.

8 Distler O, Del Rosso A, Giacomelli R, Cipriani P, Conforti ML, Guiducci S, et al. Angiogenic and angiostatic factors in systemic sclerosis: increased levels of vascular endothelial growth factor (VEGF) are a feature of earliest disease stages and are associated with the absence of fingertip ulcers. Arthritis Res 2002;4:R1 1.

9 Koch AE. The role of angiogenesis in rheumatoid arthritis: recent developments. Ann Rheum Dis 2000;59(suppl I):i65-71. 
10 Emanueli C, Minasi A, Zacheo A, Chao J, Chao L, Salis MB, et al. Local delivery of human tissue kallikrein gene accelerates spontaneous angiogenesis in mouse model of hindlimb ischemia. Circulation 2001;103:125-32.

11 Emanueli C, Zacheo A, Minasi A, Chao J, Chao L, Salis MB, et al. Adenovirusmediated human tissue kallikrein gene delivery induces angiogenesis in normoperfused skeletal muscle. Arterioscler Thromb Vasc Biol 2000;20:2379-85.

12 Madeddu P, Gherli T, Bacciu PP, Maioli M, Glorioso N. A kallikrein-like enzyme in human vascular tissue. Am J Hypertension 1993;6:344-8.

13 Emanueli C, Madeddu P. Targeting kinin receptors for the treatment of tissue ischemia. Trends Pharmacol Sci $2001 ; 22: 478-84$.

14 Wolf WC, Harley RA, Sluce D, Chao L, Chao J. Localization and expression of tissue kallikrein and kallistatin in human blood vessels. J Histochem Cytochem 1999:47:221-8.

15 Mahabeer R, Bhoola KD. Kallikrein and kinin receptor genes. Pharmacol Ther 2000;88:77-89.

16 Plendl J, Snyman C, Naidoo S, Sawant S, Mahabeer R, Bhoola KD. Expression of tissue kallikrein and kinin receptors in angiogenic microvascular endothelial cells. Biol Chem 2000;381:1103-15.

17 Porcu P, Emanueli C, Kapatsoris M, Chao J, Chao L, Madeddu P. Reversal of angiogenic growth factors upregulation by revascularization of lower limb ischemia. Circulation 2002;105:67-72.

18 Zhou GX, Chao L, Chao J. Kallistatin: a novel human tissue kallkrein inhibitor. Purification, characterization, and reactive center sequence. J Biol Chem 1992;267:25873-80

19 Xiong W, Tang CQ, Żhou GX, Chao L, Chao J. In vivo catabolism of human kallikrein-binding protein and its complex with tissue kallikrein. J Lab Clin Med 1992;119:514-21.

20 Miao RQ, Agata J, Chao L, Chao J. Kallistatin is a new inhibitor of angiogenesis and tumor growth. Blood 2002;100:3245-52.

21 Chao J, Miao RQ, Chen V, Chen LM, Chao L. Novel roles of kallistatin, a specific tissue kallikrein inhibitor, in vascular remodeling. Biol Chem 2001;382:15-21.

22 LeRoy EC, Black C, Fleischmajer R, Jablonska S, Krieg T, Medsger TA Jr, et al Scleroderma (systemic sclerosis): classification, subsets and pathogenesis. J Rheumatol 1988; 15:202-5.

23 Akesson A, Fiori G, Krieg T, van der Hoogen FHJ, Seibold JR. Assessment of skin, joint and muscle involvement. Clin Exp Rheumatol 2003;21(suppl 29):55-8.

24 Clements P, Lachenbruch P, Seibold J, White B, Weiner S, Martin R, et al. Inter and intraobserver variability of total skin thickness score (modified Rodnan TSS) in systemic sclerosis. J Rheumatol 1995:22:1281-5.

25 Cutolo M, Sulli A, Pizzorni C, Accardo S. Nailfold videocapillaroscopy assessment of microvascular damage in systemic sclerosis. J Rheumatol 2000;27:155-60.

26 Matucci Cerinic M, D'Angelo S, Denton CP, Vlachoyannopoulos P, Silver R. Assessment of lung involvement. Clin Exp Rheumatol 2003;21(suppl 29):519-23.

27 Chao J, Schmaier A, Chen LM, Yang Z, Chao L. Kallistatin, a novel human tissue kallikrein inhibitor: levels in body fluids, blood cells, and tissues in health and disease. J Lab Clin Med 1996;127:612-20.

28 Pieri L, Sassoli C, Romagnoli P, Domenici L. Use of periodate-lysineparaformaldehyde for the fixation of multiple antigens in human skin biopsies. Eur J Histochem 2002;46:365-75.

29 Naidoo Y, Snyman C, Raidoo D, Bhoola KD, Kemme M, Mueller-Esterl W. Cellular visualization of tissue prokallikrein in human neutrophils and myelocytes. Br J Haematol 1999;105:599-612.
30 Wu H. Venezie RD, Cohen WM, Jenzano JW, Featherstone GL, Lundbald RL. Identification of tissue kallikrein messenger RNA in human neutrophil. Agents Actions 1993;38:27-31.

31 Bhoola K, Figueroa CD, Worthy K. Bioregulation of kinin: kallikreins, kininogens, and kininases. Pharmacol Rev 1992;44:1-80.

32 Yousef GM, Diamandis JP. The novel human tissue kallikrein gene family: structure, function, and association to disease. Endocr Rev 2001;22:184-204.

33 Desrivieres S, Lu H, Peyri N, Soria C, Legrand Y, Menashi S. Activation of the 92 kDA type IV collagenase by tissue kallikrein. J Cell Physiol 1993; 157:587-93.

34 Linz W, Wiemer G, Gohlke P, Unger T, Scholkens BA. Contribution of kinin to the cardiovascular action of angiotensin converting enzyme inhibitors. Pharmacol Rev 1995;47:25-49.

35 Ahluwalia A, Perretti $M$. B1 receptors as a new inflammatory target: could this B the 1. Trends Pharmacol Sci 1999;20:100-3.

36 Morbidelli L, Parenti A, Giovannelli L, Granger HJ, Ledda F, Ziche M. B receptor involvement in the effect of bradykinin on venular endothelial cell proliferation and potentiation of FGF-2 effect. Br J Pharmacol 1999; 124:1286-92.

37 Carmeliet P. Mechanisms of angiogenesis and arteriogenesis. Nat Med 2000;6:389-95.

38 Hall JM. Bradykinin receptor: pharmacological and biological roles. Pharmacol Ther 1992:56:131-90.

39 Murohara T, Asahara T, Silver M, Bauters C, Masuda H, Kalka C, et al. Nitric oxide synthase modulates angiogenesis in response to tissue ischemia. J Clin Invest 1998;101:2567-8.

40 Ziche M, Morbidelli L, Masini E, Amerini S, Granger HJ, Maggi CA, et al. Nitric oxide mediates angiogenesis in vivo and endothelial cell growth and migration in vitro promoted by Substance P. J Clin Invest 1994;94:2036-44

41 Hebbar M, Peyrat JP, Hornez L, Hatron PY, Hachulla E, Devulder B. Increased concentrations of the circulating angiogenesis inhibitor endostatin in patients with systemic sclerosis. Arthritis Rheum 2000;43:889-93.

42 Matucci Cerinic M, Jaffa A, Kahaleh BM. Angiotensin converting enzyme: an in vivo and in vitro marker of endothelial injury. J Lab Clin Med 1992;120:428-33.

43 Douillet CD, Velarde V, Christopher JT, Mayfield RK, Trojanowska ME, Jaffa AA. Mechanism by which bradykinin promotes fibrosis in vascular smooth muscle cells: role of TGF- $\beta$ and MAPK. Am J Physiol Heart Circ Physiol 2000;279:H2829-37.

44 Hayashi R, Yamashita N, Matsui S, Maruyama M, Sugiyama E, Sugiyama S, et al. Bradykinin stimulates interleukin-8 production by human lung fibroblasts. Immunology 1998;95:507-11.

45 Sardi SP, Ares VR, Errasti AE, Rothlin RP. Bradykinin B1 receptors in human umbilical vein: pharmacological evidence of up-regulation, and induction by interleukin-1 beta. Eur J Pharmacol 1998;358:221-7.

46 Tiffany CW, Burch RM. Bradykinin stimulates tumor necrosis factor and interleukin-1 release from macrophages. FEBS Lett 1989;247:189-92.

47 Knox AJ, Corbett L, Stocks J, Holland E, Zhu YM, Pang L. Human airway smooth muscle cells secrete vascular endothelial growth factor: up-regulation by bradykinin via a protein kinase $C$ and prostanoid-dependent mechanism. FASEB $J$ 2001;15:2480-8.

48 Ricupero DA, Romero JR, Rishikof DC, Goldstein RH. Des-Arg 10-kallidin. Engagement of the $B 1$ receptor stimulates type I collagen synthesis via stabilization of connective tissue growth factor mRNA. J Biol Chem 2000;275:12475-80. 